\title{
Probing the Pharmacological Parameters, Molecular Docking and Quantum Computations of Plant Derived Compounds Exhibiting Strong Inhibitory Potential Against NS5 from Zika Virus
}

\author{
Nouman Rasool ${ }^{1,2 *}$, Amir Jalal ${ }^{\mathbf{3}}$, , Adnan Amjad ${ }^{4}$, , Waqar Hussain ${ }^{5}$ \\ ${ }^{1}$ University of Management and Technology - Department of Life Sciences, Lahore, Pakistan ; Dr Panjwani Center \\ for Molecular Medicine and Drug Research, International Center for Chemical and Biological Sciences, University \\ of Karachi, Karachi, 75270, Pakistan; ${ }^{3}$ Sahara Medical College Narowal Pakistan; ${ }^{4}$ University of Management \\ and Technology - Department of Chemistry, Lahore, Pakistan.; ${ }^{5}$ University of Management and Technology - \\ Department of Computer Science, Lahore, Pakistan
}

\begin{abstract}
Zika virus (ZIKV) is known for microcephaly and neurological disease in humans and the nonstructural proteins of ZIKV play a fundamental role in the viral replication. Among the seven nonstructural proteins, NS5 is the most conserved and largest protein. Two major functional domains of NS5 i.e. methyltransferase (MTase) and RNAdependent RNA polymerase (RdRp) are imperative for the virus life cycle and survival. The present study explicates the inhibitory action of phytochemicals from medicinal plants against NS5 from ZIKV, leading to the identification of potential inhibitors. The crystal structure of the protein is retrieved from RCSB protein data bank. A total of 2035 phytochemicals from 505 various medicinal plants are analysed for their pharmacological properties and pharmacokinetics. Compounds having effective drug-likeness are docked against the protein and further analysed using density functional theory approach. Among the 2035 phytochemicals, 13 are selected as potential inhibitors against MTase having high binding affinities and 17 compounds are selected for RdRp. HOMO and LUMO energies are calculated for the docked compounds within and outside binding pockets of MTase and RdRp, adapting the B3LYP hybrid exchange-correlation functional with def2-SV $(P)$ basis set. Physicochemical properties such as ionization energy, electronic chemical potential, electronegativity, electron affinity, molecular softness, molecular hardness and electrophilicity index have also been analysed for selected phytochemicals. Based upon the results, it is concluded that the selected phytochemicals are highly competent to impede the replication of the virus by inhibiting the ZIKV-NS5.
\end{abstract}

Keywords: ZIKV-NS5; Phytochemicals; Molecular Docking; DFT calculations;

*Author for correspondence: nouman.rasool@umt.edu.pk 


\section{INTRODUCTION}

Zika infection has emerged as a severe threat to human as it leads to critical, although rare, issues including microcephaly and neurological disease ${ }^{1}$. The source of this infection is Zika virus (ZIKV) which is an arbovirus and belongs to the genus Flavivirus of the family Flaviviridae ${ }^{2}$. Transmission of ZIKV is carried out through Aedes spp. mosquitoes including Ae. Apicoargenteus, Ae. africanus, Ae. aegypti, Ae. furcifer, Ae. hensilli, Ae. luteocephalus, and Ae. vitattus. The sexual transmission of disease is also possible as the replicative ZIKV is observed to be found in the semen of an infected $\operatorname{man}^{3}$. Furthermore, it is known to be transmitted through perinatal and trans-placental ways as the RNA of ZIKV is detected in the amniotic fluids samples from the fetuses of infected mothers. The infections associated with ZIKV are typically characterized by maculopapular rash, headache, fever, myalgia and conjunctivitis ${ }^{4}$.

The genome of ZIKV is a single stranded positive sense RNA which translates into a single polypeptide ${ }^{5}$. The polypeptide is truncated into ten proteins classified as structural and nonstructural proteins. Among those ten proteins, there are three structural proteins i.e. Envelope (E), Membrane (M) and Capsid (C) and seven nonstructural proteins i.e. NS1, NS2A, NS2B, NS3, NS4A, NS4B and NS5 ${ }^{6}$.

NS5 is the largest protein in the genome of ZIKV, consisting of two major domains i.e. a methyltransferase (MTase) domain at residues 1-262 and an RNA dependent RNA polymerase (RdRp) at residues 273-903. There is also an inter-domain region at residues $263-272^{7}$. MTase domain of the protein is a key target for drug discovery as it performs an essential role in the replication of the virus i.e. nucleoside-2'O and N-7 methylation of the viral RNA cap. Unfavourable effects can be observed on the progression of ZIKV by inhibition of MTase ${ }^{8}$. RdRp domain of ZIKV-NS5 initiates the RNA synthesis and generates positive and negative strand RNAs. The structure of RdRp resembles a shape analogous to hand, comprising finger thumb and palm region. There is no RdRp enzyme or its analogue structure in the human body, therefore the inhibitors of this enzyme do not cause any toxicity in the body by interacting with any other enzyme which makes this domain an optimal target of for drug designing ${ }^{9-10}$.

To date, there exists no clinical antiviral treatment against ZIKV. New research methods are adapted for identification of inhibitors against this virus ${ }^{3}$. ZIKV is known to target the neuronal cell and it is necessary for a drug to have blood brain barrier (BBB) permeability ${ }^{11}$. Through analysing the pharmacological properties and pharmacokinetics of compounds, i.e. Absorption, Distribution, Metabolism. Excretion and Toxicity, the safe and effective disposition of compound in the human body can be assessed. Those assessed compounds can be docked against target proteins easily using computational docking mechanism. It makes the process of finding inhibitors efficient as it does not requires laborious work and cost in terms of resources or money. Analysis of chemical reactivity descriptors using DFT is very important to understand chemical and biological activities of the compounds against the biological target. It helps in characterizing the electrophilic or nucleophilic nature, their ionization, potential and affinity towards the targets. Phytochemicals are produced in biosynthetic pathways of the plants, and there is a huge variety of these compounds which are known to have potential to be used against many diseases in humans ${ }^{12}$. The metabolic products of the plants have been reported to be having antiviral, antibacterial, antifungal, anticancer, and many other activities ${ }^{13}$. The present study elucidates the potential of phytochemicals from various medicinal plants, inhabited in Pakistan and India. These compounds are docked against NS5 from Zika Virus (ZIKV) to cease the replication of the virus. 


\section{MATERIAL AND METHODS}

The structures of NS5 MTase and RdRp domains were retrieved from Protein Data Bank (PDB ID: 5M5B and 5U04, respectively). A total of 2035 plant-derived phytochemicals were analysed in this study (Table 1). The compounds belonged to a variety of medicinal plants of Pakistan and India. These compounds were searched from literature review and structures were retrieved from PubChem. Initial screening was based on pharmacologic and pharmacokinetic properties to select BBB-permeable compounds. Screened compounds are docked and interactions are analysed for potentially inhibiting compounds. Molecular orbital energies based physiochemical properties are also analysed for these compounds, within and outside the pocket of proteins.

Table 1: Details of phytochemicals set

\begin{tabular}{cc}
\hline Phytochemical group & Compounds \\
\hline Alkaloids & 322 \\
\hline Terpenoids & 113 \\
\hline Aurones & 105 \\
\hline Chalcones & 101 \\
\hline Flavonoids & 378 \\
\hline Lignans & 211 \\
\hline Carboxylic acids & 255 \\
\hline Polyphenols & 301 \\
\hline Quinones & 249
\end{tabular}

\section{Assessing pharmacological properties of phytochemicals}

Pharmacological properties i.e. Absorption, Distribution, Metabolism and Excretion along with the prediction of Toxicity were used for screening the phytochemicals. These parameters also helped in evaluating the drug likeness effective disposition of the phytochemicals in the human body. The prediction of ADME profiles was carried out using SwissADME web server ${ }^{14}$. Toxicity and the Drug likeness was predicted using the PreADMET server ${ }^{15}$.

\section{Molecular docking and validation of results}

The docking study was performed to analyse the inhibition role of phytochemicals against both domains of NS5 protein i.e. MTase and RdRp. The ligand and protein preparation was performed in AutoDock Tools and docking was performed using AutoDock Vina ${ }^{16,17}$. The interactions of the compounds were analysed along with the estimation of binding energies and for further analysis of docking, $\mathrm{K}_{\mathrm{i}}$ was calculated by the equation:

$$
K_{i}=e^{\frac{\Delta G}{R x T}}
$$

Where $\Delta \mathrm{G}$ is docking energy, $\mathrm{R}$ (gas constant) is $1.9872036 \mathrm{cal} / \mathrm{mol}$ and $\mathrm{T}$ (temperature) is $298.15 \mathrm{~K}$. For validation of results and selection of potential inhibitors, natural ligands of both domains i.e. Guanosine Triphosphate (GTP) and SAdenosyl methionine (SAM) were docked with RdRp and MTase, respectively; and binding energies were compared. Compounds showing strong binding affinity as compared to the known ligands were further analysed for DFT analysis.

\section{DFT study of phytochemicals and band energy gap analysis}


Lowest Unoccupied Molecular Orbital (LUMO) and Highest Occupied Molecular Orbital (HOMO) energies of the phytochemicals were calculated using ORCA program by applying the Becke3-Lee-Yang-Parr (B3LYP) hybrid functional exchange correlation of DFT to estimate the ionization energy, electronic chemical potential, electronegativity, electron affinity, molecular softness, molecular hardness and electrophilicity index ${ }^{18}$. For these calculations, following equations were used.

$$
\begin{gathered}
\text { Ionization energy }(I E)=-\epsilon_{\text {HOMO }} \\
\text { Electron affinity }(E A)=-\epsilon_{\text {LUMO }} \\
\text { Electronegativity }(\chi)=\frac{(I E+E A)}{2} \\
\text { Electronic chemical potential }(\mu)=-\chi \\
\text { Chemical hardness }(\eta)=\frac{(I E-E A)}{2} \\
\text { Chemical softness }(\sigma)=\frac{1}{\eta} \\
\text { Electrophilicity index }(\omega)=\frac{\mu}{2 \eta}
\end{gathered}
$$

The targeted hybrid exchange correlation i.e. B3LYP is defined as:

$$
\begin{gathered}
E_{x c}^{B 3 L Y P}=E_{x}^{L D A}+a_{0}\left(E_{x}^{H F}-E_{x}^{L D A}\right)+a_{x}\left(E_{x}^{G G A}-E_{x}^{L D A}\right)+E_{c}^{L D A} \\
+a_{c}\left(E_{c}^{G G A}-E_{c}^{L D A}\right)
\end{gathered}
$$

Where $a_{0}=0.20, a_{x}=0.72$, and $a_{c}=0.81 . E_{x}^{G G A}$ is actually the generalized gradient approximation for the Becke 88 functional while the $E_{c}^{G G A}$ reflects the correlation functional of Lee-Yang-Parr. $E_{c}^{L D A}$ is the local density approximation. To analyse the reactivity of phytochemicals in the binding pocket of MTase and RdRp, band energy gaps were calculated using the expression $\mathrm{E}_{\mathrm{LUMO}}-\mathrm{E}_{\mathrm{HOMO}}{ }^{19,20}$. Phytochemicals along with the interacting residues from binding pocket were considered for the calculations and for each phytochemical, the conformer with maximum binding energy was analysed.

\section{RESULTS AND DISCUSSION}

ZIKV infection is an evolving threat to humans and has long term detrimental effects in terms of microcephaly, male sterility and neurological disease. The inhibition of ZIKV is one of the major concerns of the clinical and scientific community. Tertiary structure of ZIKV-NS5 reveals an N-terminal MTase domain, situated at the top of Cterminal RdRp domain. A Rossmann fold dominates the MTase domain with a seven stranded $\beta$-sheet, between two $\alpha$-helices ${ }^{21}$. To find the potential inhibitors, a total of 2035 phytochemicals were analysed for in this study for their inhibitory potential against ZIKV-NS5.

\section{Pharmacological properties of phytochemicals}

All 2035 compounds were analysed for their pharmacological properties and pharmacokinetics. Properties being analysed included solubility, gastrointestinal (GI) absorption, blood brain barrier (BBB) permeability, Lipinski's rules violation and toxicity. The criteria set for selecting suitable compounds was:

$($ BBB-permeability $=$ Yes $) \&($ Solubility $=$ High $) \&($ GI-absorption $=$ High $) \&$ $($ Lipinski's violations $=0) \&($ Toxicity $=$ No $)$ 
At each level of criteria set, the number of compounds selected for further analysis was reduced. Initially, out of 2035 phytochemicals, only 720 were BBB permeable. Due to the association of ZIKV with neuronal infection, it was necessary to select only those compounds which can penetrate through $\mathrm{BBB}^{22}$. From those 720 compounds, only 344 had high solubility and GI absorption. Among 344 compounds, 280 violated no rule of Lipinski and at the end, only 153 were left as non-toxic phytochemicals (Table S1). All of these parameters are necessary to evaluate the drug-likeness of a compound and helps in assessing the effective disposition of compounds in the human body $^{23-26}$.

\section{Analysis of dockings and interactions}

153 compounds, screened on the basis of pharmacological properties, were docked against both the domains of ZIKV NS5 i.e. MTase and RdRp. SAM and GTP were docked against MTase and RdRp, respectively, as they both are reported as natural ligands of the MTase and GTP27. SAM docked with MTase having a binding affinity of $-7.7 \mathrm{kcal} / \mathrm{mol}\left(\mathrm{K}_{\mathrm{i}}=2.24 \mu \mathrm{M}\right)$ whereas binding affinity of GTP was $-6.9 \mathrm{kcal} / \mathrm{mol}$ $\left(\mathrm{K}_{\mathrm{i}}=8.64 \mu \mathrm{M}\right)$ against RdRp. From 153 phytochemicals, 13 phytochemicals showed binding affinity greater than or equal to $-7.7 \mathrm{kcal} / \mathrm{mol}$ against MTase and 17 phytochemicals showed binding affinity greater than $-6.9 \mathrm{kcal} / \mathrm{mol}$ against RdRp.

Docking phytochemicals against MTase

153 compounds were docked against MTase and 13 showed binding affinity greater than the binding affinity of SAM, a natural ligand for MTase domain of NS5. Results showed that Quercetagetin, a flavonol, docked with viral enzyme having a binding affinity $-10.9 \mathrm{kcal} / \mathrm{mol}\left(\mathrm{K}_{\mathrm{i}}=0.01 \mu \mathrm{M}\right)$ which is greater than affinities of all other compounds (Table 2). The compound docked in the binding pocket of MTase interacted with $\mathrm{Val}_{30}, \mathrm{Val}_{32}, \mathrm{His}_{110}$ and $\mathrm{His}_{111}$ (Fig. 1). Chrysophanic Acid (a quinone) and Jaceidin (a flavonoid) also docked with good binding affinities i.e. $-10.2 \mathrm{kcal} / \mathrm{mol}$ $\left(\mathrm{K}_{\mathrm{i}}=0.03 \mu \mathrm{M}\right)$ and $-10.1 \mathrm{kcal} / \mathrm{mol}\left(\mathrm{K}_{\mathrm{i}}=0.04 \mu \mathrm{M}\right)$, respectively. Chrysophanic acid interacted with $\mathrm{Val}_{30}, \mathrm{Val}_{32}$ and $\mathrm{Ile}_{147}$ at the binding pocket of MTase while Gly ${ }_{81}$, Asp $_{146}$ and $\mathrm{Phe}_{133}$ were involved in the interactions with Jaceidin.

Table 2: Phytochemicals strongly inhibiting ZIKV-MTase

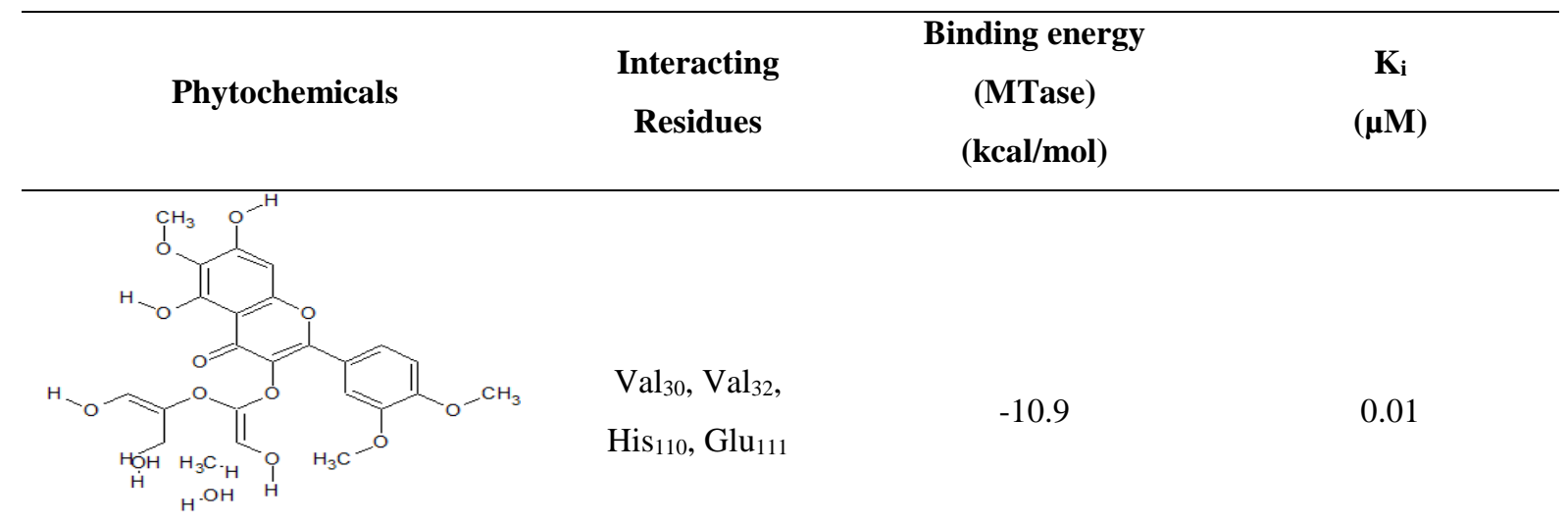

Quercetagetin 


\begin{tabular}{|c|c|c|c|}
\hline Phytochemicals & $\begin{array}{c}\text { Interacting } \\
\text { Residues }\end{array}$ & $\begin{array}{c}\text { Binding energy } \\
\text { (MTase) } \\
\text { (kcal/mol) }\end{array}$ & $\begin{array}{c}\mathbf{K}_{\mathbf{i}} \\
(\boldsymbol{\mu M})\end{array}$ \\
\hline & $\mathrm{Val}_{30}, \mathrm{Val}_{32}, \mathrm{Ile}_{147}$ & -10.2 & 0.03 \\
\hline
\end{tabular}

Chrysophanic Acid<smiles>CC1=C(c2ccc(O)c(O)c2)Oc2cc(O)c(C)c(C)c2C1O</smiles>

Jaceidin<smiles>COc1ccc(C2CC(=O)c3c(OC)cc(OC)c(CC=C(C)C)c3O2)cc1O</smiles>

Methylglovanon<smiles>CC1(O)CCC2(C)C(O)C[C@H](CC(=O)O)CC12</smiles>

Caninnot<smiles>OC1=CC(=C2C=CC(O)=C(O)C2)Oc2cc(O)cc(O)c21</smiles>

Gly $_{81}$, Asp $_{146}$,

$\mathrm{Phe}_{133}$

Lys $_{105}$, Asp $_{131}$,

$\mathrm{Ile}_{147}$

$\mathrm{Thr}_{104}, \mathrm{Asp}_{131}$,

Phe $_{133}$

$-8.9$

0.29
$-10.1$

0.04

0.11

$-9.5$

(2) 


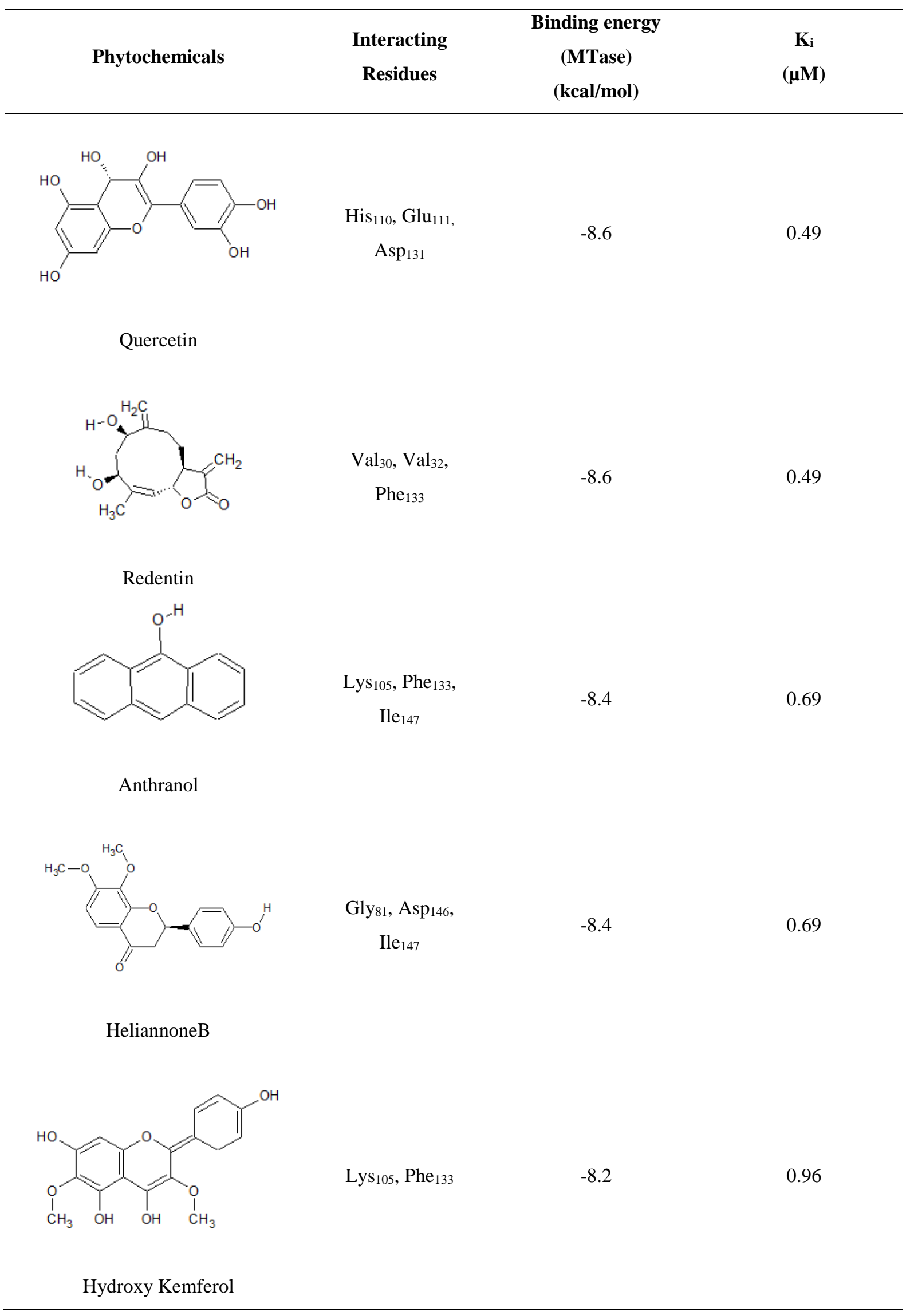




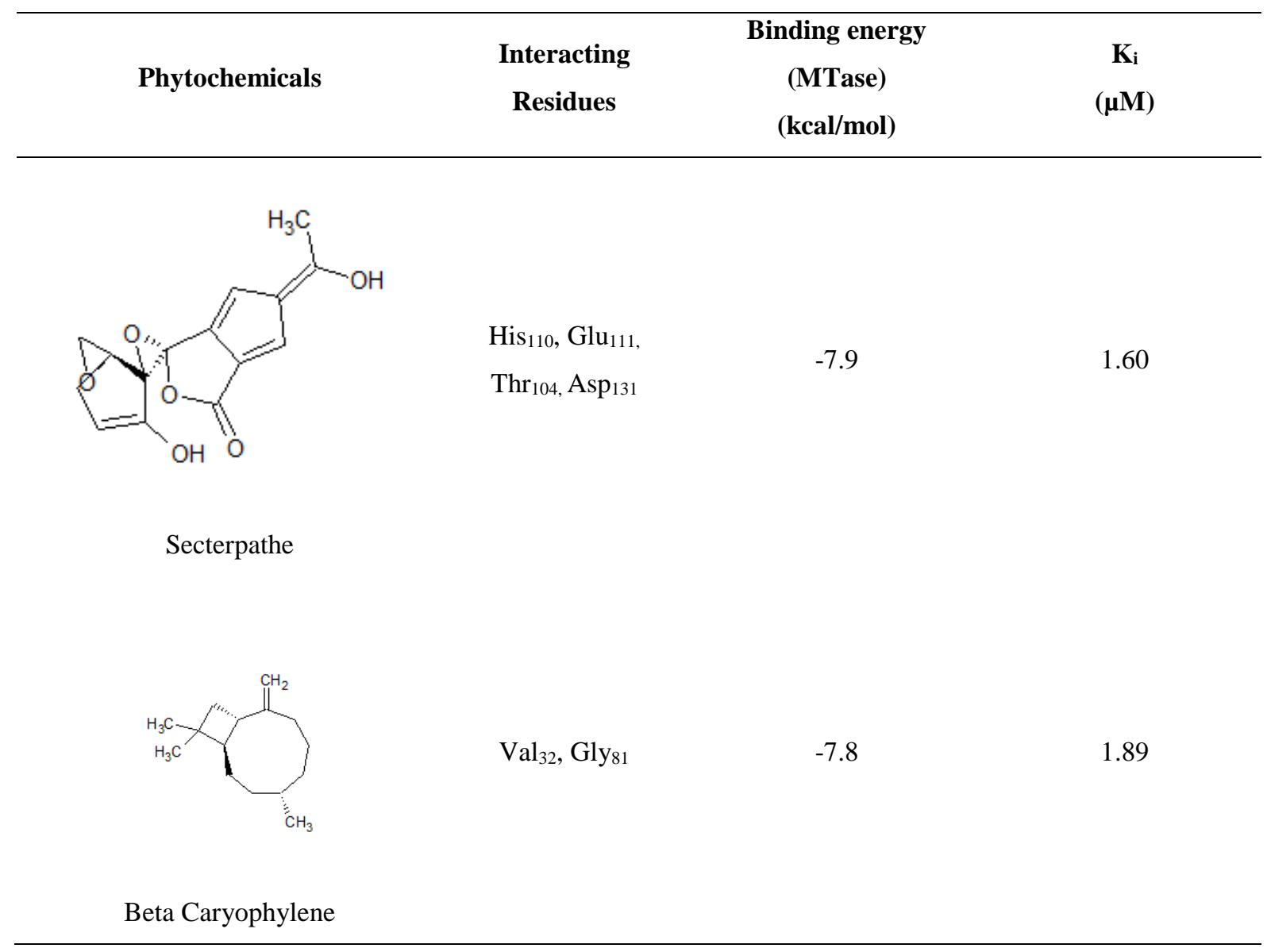

Previously, ZIKV-MTase has been targeted using various compounds. Byler et al., (2016) reported that cimiphenol, cimiracemate B, and rosemarinic acid exhibited relatively strong docking energies as among 2263 phytochemicals docked against MTase in that study ${ }^{28}$. ZINC library compounds were analysed against ZIKV-MTase and results of docking were compared with BG323, a known inhibitor of MTase. It is reported that ZINC64717952 showed high binding affinity against MTase as compared to that of $\mathrm{BG} 323^{3}$.

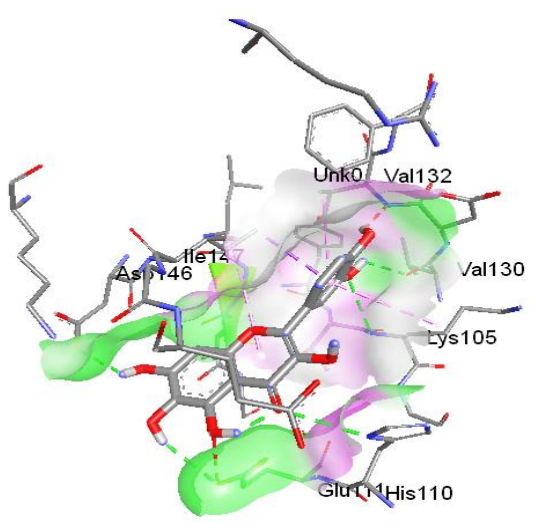

(a)

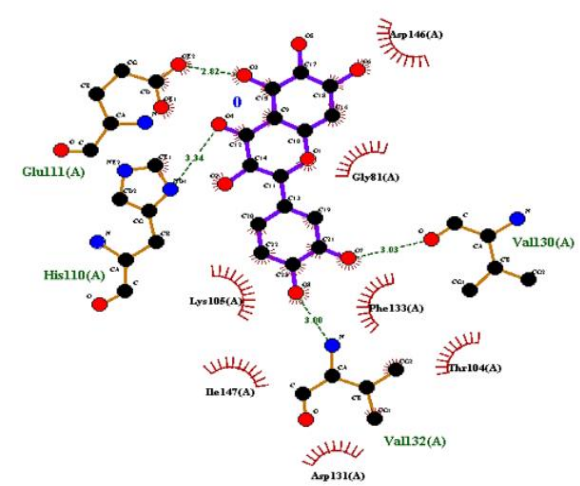

(b)

Figure 1: Interaction of Quercetagetin within binding pocket of ZIKV MTase (a) 3D view of pocket (b) Interaction plot 


\section{Docking phytochemicals against RdRp}

Among all 153 compounds docked against RdRp, 17 showed binding affinity greater than the binding affinity of GTP, a natural ligand for RdRp domain of NS5. Results showed that Ferulic Acid, a phenol, docked with binding affinity $-9.0 \mathrm{kcal} / \mathrm{mol}$, greater than affinities of all other compounds (Table 3). The compound docked in the binding pocket of $\mathrm{RdRp}$ interacting with $\mathrm{Tyr}_{609}$, $\mathrm{Ile}_{799}$ and His 800 (Fig. 2). 1Aminocyclopropane-1-carboxylic acid and Cinnamic acid, both carboxylic acids in nature, docked with binding affinities $-8.9 \mathrm{kcal} / \mathrm{mol}\left(\mathrm{K}_{\mathrm{i}}=0.29 \mu \mathrm{M}\right)$ and $-8.8 \mathrm{kcal} / \mathrm{mol}$ $\left(\mathrm{K}_{\mathrm{i}}=0.35 \mu \mathrm{M}\right)$, respectively. 1-Aminocyclopropane-1-carboxylic acid interacted with $\mathrm{Tyr}_{609}, \mathrm{Asn}_{612}, \mathrm{Ser}_{798}, \mathrm{Il}_{799}$ and His 800 residues at the RNA tunnel of ZIKV-RdRp. Moreover, Cinnamic acid docked at the RNA tunnel of RdRp by interacting with $\mathrm{Tyr}_{609}, \mathrm{Asn}_{612}, \mathrm{Ser}_{663}, \mathrm{Asp}_{665}$, Asp $_{666}$ and Cys711.

Table 3: Phytochemicals strongly inhibiting ZIKV-RdRp

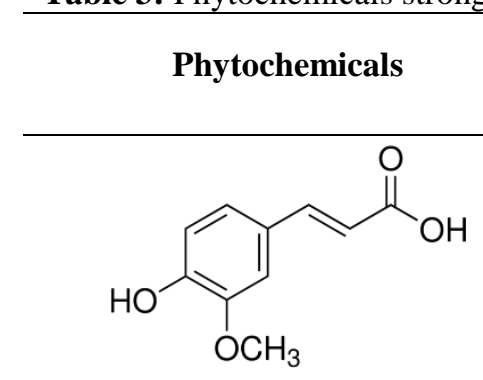

Ferulic Acid<smiles>NC1(C(=O)O)CC1</smiles>

\section{Interacting}

residues
Binding energy (RdRp)

(kcal/mol)

\section{Ki}

( $\mu \mathrm{M})$

$\mathrm{Tyr}_{609}, \operatorname{Asn}_{612}$,

Ser $_{663}$, Gly $_{664}$,

Asp665, Asp666,

$-9.0$

0.25

Cys $_{711}$, Ser $_{798}$,

Ile $_{799}$, His 800

$\mathrm{Tyr}_{609}$, Asn $_{612}$,

$\mathrm{Ser}_{798}, \mathrm{Ile}_{799}, \mathrm{His} 800$

1-Aminocyclopropane-1carboxylic acid<smiles>O=C(O)/C=C/c1ccccc1</smiles>

Cinnamic Acid

$\mathrm{Tyr}_{609}, \mathrm{Asn}_{612}$,

Ser $_{663}$, Asp $_{665}$,

0.35 


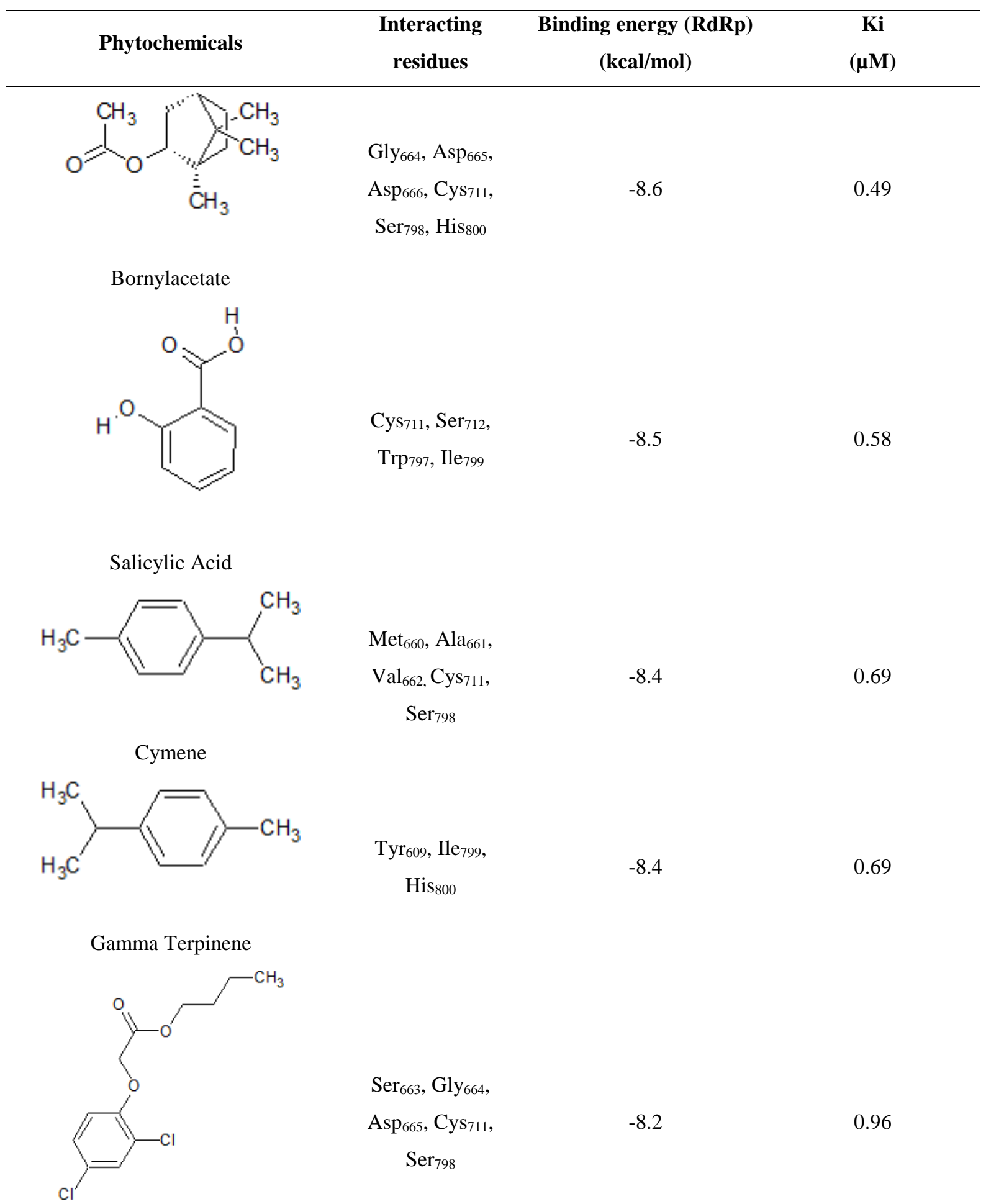

Kolin 


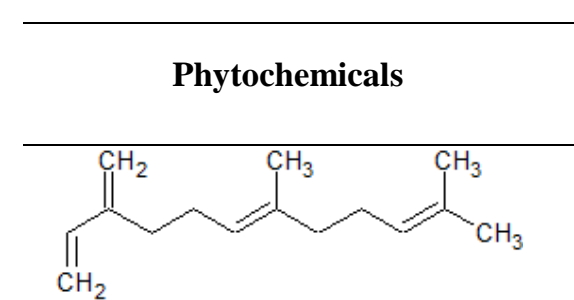

Fernesene<smiles>CC1(C)C2CC=C(C=O)C1C2</smiles>

Myrtenal<smiles>Cc1ccccc1</smiles>

Asn $_{612}$, Gly $_{664}$,

$\mathrm{Thr}_{796}$ Asn $_{612}$, Gly $_{664}$

$\mathrm{Thr}_{796}$

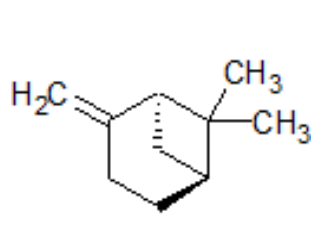

Beta Pinene<smiles>Cc1ccc(C)cc1</smiles>

Xylene

Met660, Val $_{662}$,

His800

Alphaprodine

Val $_{662}$, Cys711,

$\operatorname{Ser}_{798}$ $(\boldsymbol{\mu M})$

$-8.0$

His $_{800}$

(kcal/mol)

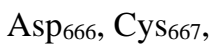

(2) 


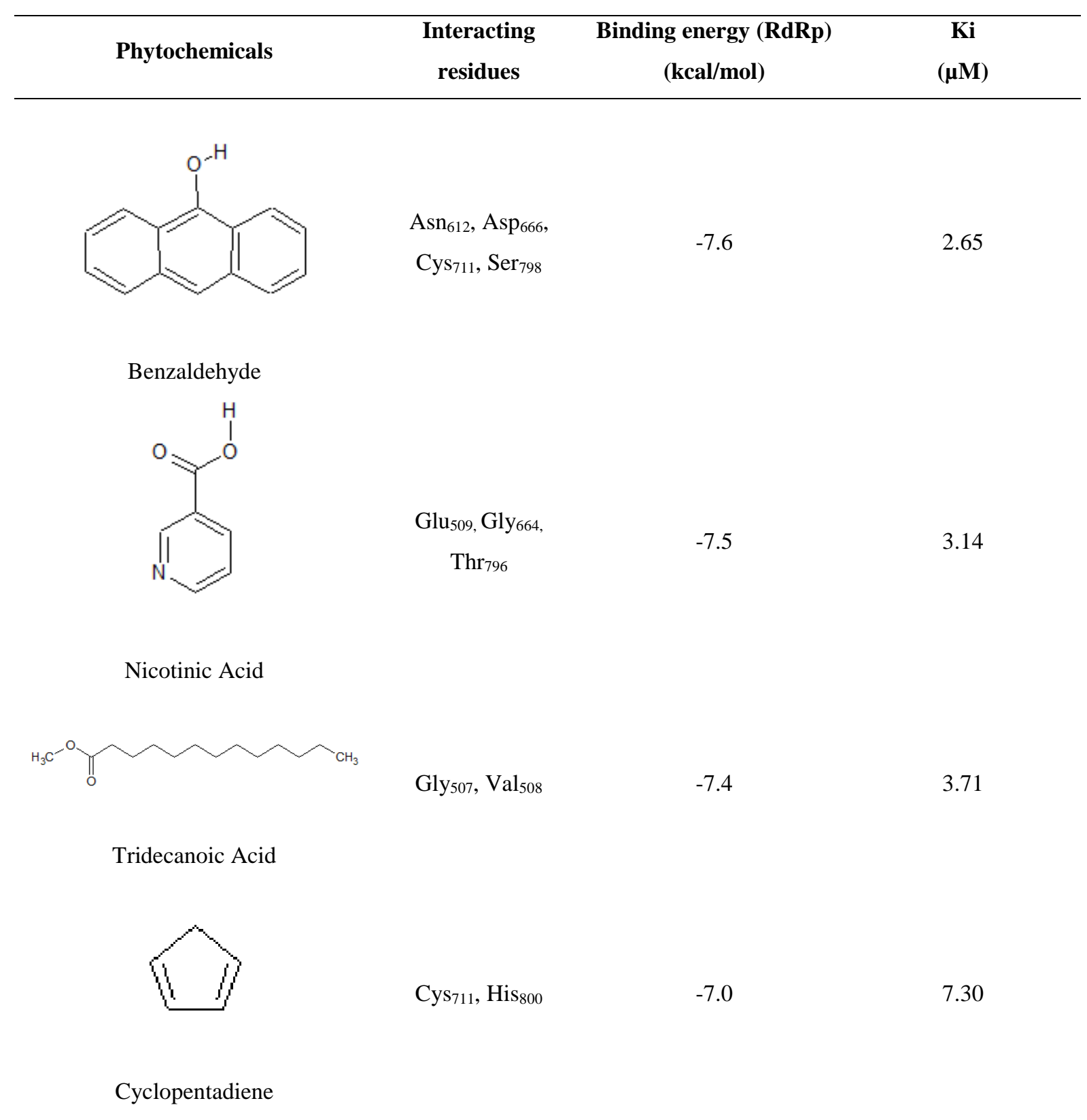




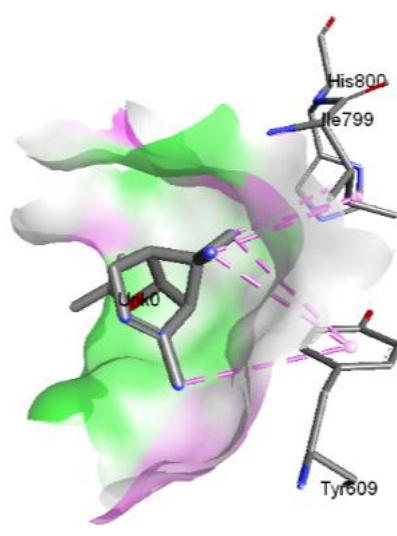

(a)

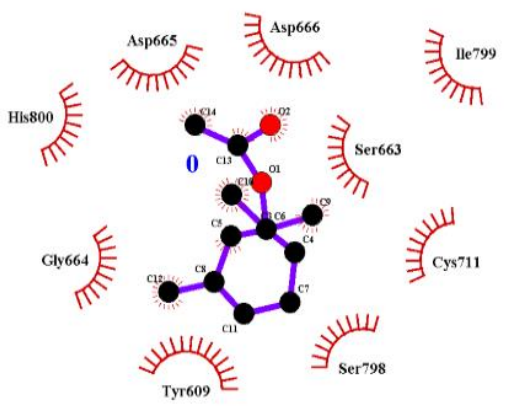

(b)

Figure 2: Interaction of Ferulic Acid within RNA Tunnel of ZIKV RdRp (a) 3D view of pocket (b) Interaction plot

ZIKV-RdRp is a potential target for drug discovery as RdRp enzyme or its analogue structure in the human body are not present, therefore the inhibitors of this enzyme do not cause any toxicity in the body by interacting with any other enzyme ${ }^{9}$. In a previous study, Prenylatedchalcone, 2',4,4'-trihydroxy-3,3'-diprenylchalcone, bisindole and flinderoleB are reported to potentially inhibit ZIKV-RdRp domain with strong binding affinities. Among 2263 phytochemicals, these four compounds were screened based on high binding energies ${ }^{28}$. While targeting this enzyme with ZINC library, it was observed that ZINC39563464 showed the strong binding affinity to RdRp. The score was also higher as compared to that of Ribavirin, a potential inhibitor of $\mathrm{RdRp}^{3}$. In the present study, Quercetagetin was docked with MTase, having highest binding affinity as compared to that of all other compounds, however, in another study, Quercetagetin was reported as inhibitor of HCV-NS5B, which is also an RdRp ${ }^{29}$. This illustrates that Quercetagetin showed binding affinity $<-6.9 \mathrm{kcal} / \mathrm{mol}$ when docked with ZIKV-RdRp.

\section{Quantum mechanistic analysis of selected 30 compounds}

30 phytochemicals showed strong inhibitory potential against the NS5 protein of ZIKV and were selected for further analysis. Two types of DFT studies were conducted for these compounds i.e. within the binding pockets and outside the binding pockets of NS5. Ionization energy, electronic chemical potential, electronegativity, electron affinity, molecular softness, molecular hardness and electrophilicity index were calculated by targeting the compounds only (Table 4). 
Table 4: Quantum mechanistic analysis of phytochemicals

\begin{tabular}{|c|c|c|c|c|c|c|c|c|c|}
\hline Phytochemicals & $\begin{array}{l}\text { LUMO } \\
(\mathrm{eV})\end{array}$ & $\begin{array}{l}\text { HOMO } \\
(\mathrm{eV})\end{array}$ & $\begin{array}{l}\text { Ionization } \\
\text { Energy } \\
(\mathrm{eV})\end{array}$ & $\begin{array}{l}\text { Electron } \\
\text { Affinity } \\
(\mathrm{eV})\end{array}$ & $\begin{array}{l}\text { Electronegativity } \\
\text { (eV) }\end{array}$ & $\begin{array}{l}\text { Electronic } \\
\text { chemical } \\
\text { potential } \\
(\mathrm{eV})\end{array}$ & $\begin{array}{l}\text { Hardness } \\
\text { (eV) }\end{array}$ & $\begin{array}{l}\text { Softness } \\
(\mathrm{eV})\end{array}$ & $\begin{array}{l}\text { Electrophilicity } \\
\text { Index }\end{array}$ \\
\hline $\begin{array}{l}1- \\
\text { Aminocyclopropan } \\
\text { e-1-carboxylic } \\
\text { acid }\end{array}$ & -0.245 & -0.365 & 0.365 & 0.245 & 0.305 & -0.305 & 0.060 & 16.667 & -2.542 \\
\hline Alphaprodine & -0.194 & -0.319 & 0.319 & 0.194 & 0.257 & -0.257 & 0.063 & 16.000 & -2.052 \\
\hline Anthranol & -0.238 & -0.369 & 0.369 & 0.238 & 0.304 & -0.304 & 0.066 & 15.267 & -2.317 \\
\hline Benzaldehyde & -0.179 & -0.304 & 0.304 & 0.179 & 0.242 & -0.242 & 0.063 & 16.000 & -1.932 \\
\hline Beta Caryophylene & -0.202 & -0.334 & 0.334 & 0.202 & 0.268 & -0.268 & 0.066 & 15.152 & -2.030 \\
\hline Beta Pinene & -0.296 & -0.421 & 0.421 & 0.296 & 0.359 & -0.359 & 0.063 & 16.000 & -2.868 \\
\hline Bornylacetate & -0.260 & -0.380 & 0.380 & 0.260 & 0.320 & -0.320 & 0.060 & 16.667 & -2.667 \\
\hline Caninnot & -0.202 & -0.325 & 0.325 & 0.202 & 0.264 & -0.264 & 0.062 & 16.260 & -2.142 \\
\hline $\begin{array}{l}\text { Chrysophanic } \\
\text { Acid }\end{array}$ & -0.232 & -0.346 & 0.346 & 0.232 & 0.289 & -0.289 & 0.057 & 17.544 & -2.535 \\
\hline Cinnamic Acid & -0.244 & -0.363 & 0.363 & 0.244 & 0.304 & -0.304 & 0.060 & 16.807 & -2.550 \\
\hline Cyclopentadiene & -0.146 & -0.295 & 0.295 & 0.146 & 0.221 & -0.221 & 0.075 & 13.423 & -1.480 \\
\hline Cymene & -0.154 & -0.275 & 0.275 & 0.154 & 0.215 & -0.215 & 0.061 & 16.529 & -1.773 \\
\hline Fernesene & -0.176 & -0.299 & 0.299 & 0.176 & 0.238 & -0.238 & 0.062 & 16.260 & -1.931 \\
\hline Ferulic Acid & -0.209 & -0.328 & 0.328 & 0.209 & 0.269 & -0.269 & 0.060 & 16.807 & -2.256 \\
\hline Gamma Terpinene & -0.214 & -0.336 & 0.336 & 0.214 & 0.275 & -0.275 & 0.061 & 16.393 & -2.254 \\
\hline HeliannoneB & -0.194 & -0.326 & 0.326 & 0.194 & 0.260 & -0.260 & 0.066 & 15.152 & -1.970 \\
\hline Hydroxy Kemferol & -0.128 & -0.260 & 0.260 & 0.128 & 0.194 & -0.194 & 0.066 & 15.152 & -1.470 \\
\hline Jaceidin & -0.175 & -0.290 & 0.290 & 0.175 & 0.233 & -0.233 & 0.058 & 17.391 & -2.022 \\
\hline Kolin & -0.257 & -0.379 & 0.379 & 0.257 & 0.318 & -0.318 & 0.061 & 16.393 & -2.607 \\
\hline Luteolin & -0.293 & -0.422 & 0.422 & 0.293 & 0.358 & -0.358 & 0.065 & 15.504 & -2.771 \\
\hline Methylglovanon & -0.167 & -0.289 & 0.289 & 0.167 & 0.228 & -0.228 & 0.061 & 16.393 & -1.869 \\
\hline Myrtenal & -0.158 & -0.282 & 0.282 & 0.158 & 0.220 & -0.220 & 0.062 & 16.129 & -1.774 \\
\hline Nicotinic Acid & -0.253 & -0.378 & 0.378 & 0.253 & 0.316 & -0.316 & 0.063 & 16.000 & -2.524 \\
\hline Quercetagetin & -0.230 & -0.341 & 0.341 & 0.230 & 0.286 & -0.286 & 0.056 & 18.018 & -2.572 \\
\hline Quercetin & -0.211 & -0.341 & 0.341 & 0.211 & 0.276 & -0.276 & 0.065 & 15.385 & -2.123 \\
\hline
\end{tabular}




\begin{tabular}{|c|c|c|c|c|c|c|c|c|c|}
\hline Redentin & -0.292 & -0.423 & 0.423 & 0.292 & 0.358 & -0.358 & 0.066 & 15.267 & -2.729 \\
\hline Salicylic Acid & -0.160 & -0.281 & 0.281 & 0.160 & 0.221 & -0.221 & 0.061 & 16.529 & -1.822 \\
\hline Secterpathe & -0.197 & -0.329 & 0.329 & 0.197 & 0.263 & -0.263 & 0.066 & 15.152 & -1.992 \\
\hline Tridecanoic Acid & -0.272 & -0.421 & 0.421 & 0.272 & 0.347 & -0.347 & 0.075 & 13.423 & -2.326 \\
\hline Xylene & -0.230 & -0.355 & 0.355 & 0.230 & 0.293 & -0.293 & 0.063 & 16.000 & -2.340 \\
\hline
\end{tabular}


Among all the compounds, Quercetagetin showed the most effective properties i.e. hardness $(0.056 \mathrm{kcal} / \mathrm{mol})$, electrophilicity index $(-2.572 \mathrm{kcal} / \mathrm{mol})$ and electronic chemical potential $(-0.286 \mathrm{kcal} / \mathrm{mol})$. Chemical hardness of a compound illustrates its stability and reactivity. The larger band energy gaps reflect hardness and stability of the compounds but leads to lower reactivity. Smaller band energy gaps reflect softness and high reactivity of compounds. The electronic chemical potential is actually the negative value of electronegativity and the greater electronic chemical potential reflects less stability and high reactivity of the compounds. The mechanism and capacity of electrons acceptance is measured through electrophilicity index ${ }^{30,31}$. It measures the stabilization in energy after the chemical reaction through electron acceptance and donation ${ }^{32}$. Such analysis has been previously conducted by Gopalakrishnan et al., (2014) to analyse the phytochemical constituents of the Cucumis trigonus and Cucumis sativus ${ }^{33}$.

For analysing reactivity, phytochemicals and the binding pocket residues was the point of interest for energy calculations. The quantum mechanistic analysis was carried out on the ligand-NS5 domain conformation selected in the docking analysis. Results revealed that Quercetagetin was most reactive compound within binding pocket of NS5 as band energy gap was narrow as compared to others i.e. $0.119 \mathrm{eV}$, while the natural ligand i.e. SAM showed least reactivity as band energy gap was $0.173 \mathrm{eV}$, lowest among all the other 13 compounds (Table 5). For RdRp domain, Ferulic Acid had the narrow band energy gap i.e. $0.114 \mathrm{eV}$ reflecting its higher reactivity potential with the binding pocket residues of RdRp, while the natural ligand i.e. GTP showed least reactivity as band energy gap was $0.182 \mathrm{eV}$, lowest among all the other 17 compounds (Table 6).

Table 5: Band energy gaps analysis in the binding pocket of MTase

\begin{tabular}{llll}
\hline Phytochemicals & Eumo $(\mathbf{e V})$ & Eномо $(\mathbf{e V})$ & Band energy gap ( $\mathbf{E})(\mathbf{e V})$ \\
\hline Quercetagetin & -0.186 & -0.305 & 0.119 \\
\hline Chrysophanic Acid & -0.295 & -0.417 & 0.122 \\
\hline Jaceidin & -0.269 & -0.393 & 0.124 \\
\hline Methylglovanon & -0.220 & -0.346 & 0.126 \\
\hline Caninnot & -0.157 & -0.305 & 0.148 \\
\hline Luteolin & -0.158 & -0.306 & 0.148 \\
\hline Qurecitin & -0.237 & -0.387 & 0.150 \\
\hline Redentin & -0.188 & -0.339 & 0.151 \\
\hline Anthranol & -0.180 & -0.332 & 0.152 \\
\hline HeliannoneB & -0.227 & -0.379 & 0.152 \\
\hline Hydroxy Kemferol & -0.131 & -0.290 & 0.159 \\
\hline Secterpathe & -0.195 & -0.360 & 0.165 \\
\hline Beta Caryophylene & -0.285 & -0.455 & 0.170 \\
\hline S-Adenosyl methionine & -0.291 & -0.464 & 0.173 \\
\hline
\end{tabular}


Table 6: Band energy gaps analysis in the binding pocket of RdRp

\begin{tabular}{|c|c|c|c|}
\hline Phytochemicals & ELumo $(\mathrm{eV})$ & $\mathbf{E}_{\text {номо }}(\mathrm{eV})$ & Band energy gap $(\Delta E)(e V)$ \\
\hline Ferulic Acid & -0.274 & -0.388 & 0.114 \\
\hline $\begin{array}{l}\text { 1-Aminocyclopropane-1- } \\
\text { carboxylic acid }\end{array}$ & -0.153 & -0.27 & 0.117 \\
\hline Cinnamic Acid & -0.137 & -0.263 & 0.126 \\
\hline Bornylacetate & -0.292 & -0.426 & 0.134 \\
\hline Salicylic Acid & -0.305 & -0.444 & 0.139 \\
\hline Cymene & -0.224 & -0.364 & 0.140 \\
\hline Gamma Terpinene & -0.260 & -0.401 & 0.141 \\
\hline Kolin & -0.186 & -0.337 & 0.151 \\
\hline Fernesene & -0.284 & -0.436 & 0.152 \\
\hline Myrtenal & -0.175 & -0.327 & 0.152 \\
\hline Alphaprodine & -0.282 & -0.434 & 0.152 \\
\hline Beta Pinene & -0.221 & -0.375 & 0.154 \\
\hline Xylene & -0.115 & -0.272 & 0.157 \\
\hline Benzaldehyde & -0.119 & -0.279 & 0.160 \\
\hline Nicotinic Acid & -0.256 & -0.419 & 0.163 \\
\hline Tridecanoic Acid & -0.252 & -0.417 & 0.165 \\
\hline Cyclopentadiene & -0.162 & -0.333 & 0.171 \\
\hline Guanosine Triphosphate & -0.169 & -0.351 & 0.182 \\
\hline
\end{tabular}

In literature, no study has been reported previously targeting the analysis of compound reactivity within binding pocket of ZIKV proteins. However, DFT based analysis is reported in some other studies and the band energy gaps of the present study are also within same range of those reported in previous studies ${ }^{34,35}$. The lower band energy gap reflects higher reactivity of compounds as the $\mathrm{E}_{\mathrm{LUMO}}$ and $\mathrm{E}_{\mathrm{HOMO}}$ are responsible for the charges transferred in a chemical reaction ${ }^{36}$. In the present study, the thirty screened out phytochemicals were evaluated based upon DFT analysis and the lower band energy gap of molecular orbital energies illustrated the higher reactivity of these phytochemicals ${ }^{37}$. This validates the potential of the thirty phytochemicals against ZIKV-NS5. 


\section{CONCLUSION}

The infection associated with ZIKV leads to long term effects in terms of various diseases, specifically neurological ones. The Zika infection is an emerging threat and no clinically approved antiviral treatment is discovered yet to cure the disease. Computational approaches for drug development are proven to be effective and time efficient as these are not based on costly and hectic laborious works. In drug discovery, the molecular dynamics simulations help in the study of the motions of biological macromolecules such as proteins and nucleic acids. Computational mechanisms of biological targets and their associated small-molecule ligands can play an important role in drug discovery; including the identification of binding sites, virtual screening of numerous compounds libraries and estimation of ligand binding energies. The docking of inhibitors with the enzymes elucidate the mechanism of inhibition along with the specificity and efficiency of that inhibitor. It was aim of the present study to identify potential inhibitors of the virus replication and the most fundamental protein i.e. NS5 was targeted in this study using 2053 plant derived compounds. The successfully docked compounds with high binding affinity and reactivity are reported against both the domains of NS5 i.e. MTase and RdRp. These are all BBB-permeable and can reach the central nervous system as ZIKV targets the neuronal cells. Due to higher affinities and reactivity of these compounds against NS5, these 30 compounds have potential inhibitory activity against ZIKV and can be further analysed using in vitro and in vivo approach to elucidate their inhibitory mechanism against ZIKV.

\section{REFERENCES}

1. Hayes EB. Zika virus outside Africa. Emerg Infect Dis. 2009; 15: 1347.

2. Shi PY. Molecular virology and control of flaviviruses. Horizon Scientific Press; 2009

3. Ramharack P, Soliman ME. Zika virus NS5 protein potential inhibitors: an enhanced in silico approach in drug discovery. J Biomol Struct Dyn. 2017; 1-16.

4. Musso D, Nilles EJ, Cao-Lormeau VM. Rapid spread of emerging Zika virus in the Pacific area. Clin Microbiol Infect. 2014; 20: O595-O596.

5. Campos GS, Bandeira AC, Sardi SI. Zika virus outbreak, Bahia, Brazil. Emerg Infect Dis. 2015; 21: 1885.

6. Haddow AD, Schuh AJ, Yasuda CY, Kasper MR, Heang V, Huy R, Weaver SC. Genetic characterization of Zika virus strains: geographic expansion of the Asian lineage. PLoS Negl Trop Dis. 2012; 6: e1477.

7. Zou XW, Liu YC, Hsu NS, Huang CJ, Lyu SY, Chan HC, Tsai MD. Structure and mechanism of a nonhaem-iron SAM-dependent C-methyltransferase and its engineering to a hydratase and an O-methyltransferase. Acta Crystallogr D Biol Crystallogr. 2014; 70:15491560.

8. Brecher M, Chen H, Liu B, Banavali NK, Jones SA, Zhang J, Li H. Novel broad spectrum inhibitors targeting the flavivirus methyltransferase. PLoS One. 2015; 10: e0130062.

9. Anusuya S, Velmurugan D, Gromiha MM. Identification of dengue viral RNA-dependent RNA polymerase inhibitor using computational fragment-based approaches and molecular dynamics study. J Biomol Struct Dyn. 2016; 34: 1512-1532.

10. Papageorgiou L, Loukatou S, Koumandou VL, Makałowski W, Megalooikonomou V, Vlachakis D, Kossida S. Structural models for the design of novel antiviral agents against Greek Goat Encephalitis. Peer J. 2014; 2:e664. 
11. Tang H, Hammack C, Ogden SC, Wen Z, Qian X, Li Y, Christian KM. Zika virus infects human cortical neural progenitors and attenuates their growth. Cell Stem Cell. 2016; 18: 587590.

12. Williamson EM. Synergy and other interactions in phytomedicines. Phytomed. 2001; 8:401-410.

13. Briskin DP. Medicinal plants and phytomedicines. Linking plant biochemistry and physiology to human health. Plant Physiol. 2000; 124:507-14.

14. Daina A, Michielin O, Zoete V. SwissADME: a free web tool to evaluate pharmacokinetics, drug-likeness and medicinal chemistry friendliness of small molecules. Sci Rep 2017; 7:42717.

15. Lee SK, Lee IH, Kim HJ, Chang GS, Chung JE, No KT. The PreADME Approach: Webbased program for rapid prediction of physico-chemical, drug absorption and drug-like properties. EuroQSAR 2002 Designing Drugs and Crop Protectants: processes, problems and solutions. 2003; 418-20.

16. Hussain W, Qaddir I, Mahmood S, Rasool N. In silico targeting of non-structural 4B protein from dengue virus 4 with spiropyrazolopyridone: study of molecular dynamics simulation, ADMET and virtual screening. VirusDisease. 2018; 29:147-156.

17. Trott O, Olson AJ. AutoDock Vina: improving the speed and accuracy of docking with a new scoring function, efficient optimization, and multithreading. J Comp Chem. 2010; 31:45561.

18. Neese F. The ORCA program system. Wiley Interdiscip Rev Comput Mol Sci. 2012; $2: 73-8$

19. Qaddir I, Rasool N, Hussain W, Mahmood S. Computer-aided analysis of phytochemicals as potential dengue virus inhibitors based on molecular docking, ADMET and DFT studies. Journal of Vector Borne Diseases. 2017; 54:255.

20. Rasool N, Iftikhar S, Amir A, Hussain W. Structural and quantum mechanical computations to elucidate the altered binding mechanism of metal and drug with pyrazinamidase from Mycobacterium tuberculosis due to mutagenicity. Journal of molecular graphics \& modelling. 2017; 80:126-31.

21. Wang B, Tan XF, Thurmond S, Zhang ZM, Lin A, Hai R, Song J. The structure of Zika virus NS5 reveals a conserved domain conformation. Nat Commun. 2017; 8.

22. Millichap J. Zika virus infection and microcephaly. Ped Neurol Briefs. 2016; 30.

23. Delaney JS. ESOL: estimating aqueous solubility directly from molecular structure. $J$ Chem Inf Comput Sci. 2004; 44:1000-5.

24. Kimura T, Higaki K. Gastrointestinal transit and drug absorption. Biological and Pharm Bull. 2002; 25:149-64.

25. Lipinski CA, Lombardo F, Dominy BW, Feeney PJ. Experimental and computational approaches to estimate solubility and permeability in drug discovery and development settings. Adv Drug Deliv Rev. 1997; 23:3-25.

26. Tran N. Blood-Brain Barrier. Encyclopedia of Clinical Neuropsychology. Springer New York; 2011.

27. Godoy AS, Lima GM, Oliveira KI, Torres NU, Maluf FV, Guido RV, Oliva G. Crystal structure of Zika virus NS5 RNA-dependent RNA polymerase. Nat Commun. 2017; 8.

28. Byler KG, Ogungbe IV, Setzer WN. In-silico screening for anti-Zika virus phytochemicals. J Mol Graph Model. 2016; 69:78-91.

29. Ahmed-Belkacem A, Guichou JF, Brillet R, Ahnou N, Hernandez E, Pallier C, Pawlotsky JM. Inhibition of RNA binding to hepatitis $\mathrm{C}$ virus RNA-dependent RNA polymerase: a new mechanism for antiviral intervention. Nucleic Acids Research. 2014; 42:9399-409.

30. Parr RG, Szentpaly LV, Liu S. Electrophilicity index. J Am Chem Soc. 1999; 121: $1922-$ 1924.

31. Vektariene A, Vektaris G, Svoboda J. A theoretical approach to the nucleophilic behavior of benzofused thieno [3, 2-b] furans using DFT and HF based reactivity descriptors. ARKIVOC: Online J Org Chem. 2009. 
32. Liu S. Dynamic behavior of chemical reactivity indices in density functional theory: A Bohn-Oppenheimer quantum molecular dynamics study. J Chem Sci. 2005; 117: 477-483.

33. Gopalakrishnan SB, Kalaiarasi T, Subramanian R. Comparative DFT Study of Phytochemical Constituents of the Fruits of Cucumis trigonus Roxb. and Cucumis sativus Linn. J Comp Method Phy. 2014; 2014.

34. Gogoi D, Baruah VJ, Chaliha AK, Kakoti BB, Sarma D, Buragohain AK. Identification of novel human renin inhibitors through a combined approach of pharmacophore modelling, molecular DFT analysis and in silico screening. Comp Biol Chem. 2017; 69:28-40.

35. Kavitha R, Karunagaran S, Chandrabose SS, Lee KW, Meganathan C. Pharmacophore modeling, virtual screening, molecular docking studies and density functional theory approaches to identify novel ketohexokinase (KHK) inhibitors. BioSys. 2015; 138:39-52.

36. Eroglu E, Türkmen H. A DFT-based quantum theoretic QSAR study of aromatic and heterocyclic sulfonamides as carbonic anhydrase inhibitors against isozyme, CA-II. $J$ Mol Graph Model. 2007; 26:701-8.

37. Ai C, Li Y, Wang Y, Li W, Dong P, Ge G, Yang L. Investigation of binding features: effects on the interaction between CYP2A6 and inhibitors. J Comp Chem. 2010; 31:1822-31. 